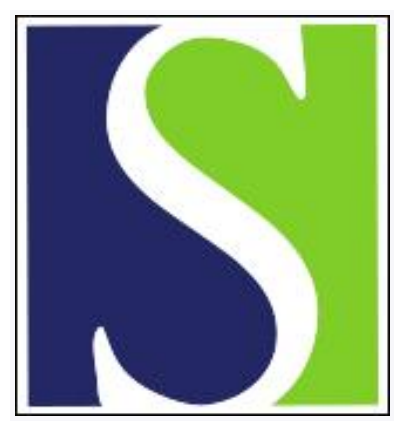

Scand J Work Environ Health 2002;28(2):124-132

https://doi.org/10.5271/sjweh.656

Issue date: Apr 2002

Female fertility in relation to the consumption of fish contaminated with persistent organochlorine compounds by Axmon A, Rylander L, Strömberg U, Hagmar L

Affiliation: Department of Occupational and Environmental Medicine, Insitute of Laboratory Medicine, University Hospital, SE-221 85 Lund, Sweden. anna.axmon@ymed.lu.se

Refers to the following texts of the Journal: 2000;26(3):199-206 1995;21(5):368-375 1995;21(2):106-115

Key terms: consumption of fish; female; fertility; food contamination; miscarriage; PCP; persistent organochlorine compound; polychlorinated biphenyl; stillbirth; time to pregnancy

This article in PubMed: www.ncbi.nlm.nih.gov/pubmed/12019589 


\title{
Female fertility in relation to the consumption of fish contaminated with persistent organochlorine compounds
}

\author{
by Anna Axmon, LicMedSc, ${ }^{1}$ Lars Rylander, DrMedSc, ${ }^{1}$ Ulf Strömberg, PhD, ${ }^{1}$ Lars Hagmar, MD ${ }^{1}$
}

\begin{abstract}
Axmon A, Rylander L, Strömberg U, Hagmar L. Female fertility in relation to the consumption of fish contaminated with persistent organochlorine compounds. Scand J Work Environ Health 2002;28(2):124-132.

Objectives The purpose of the study was to assess the effect of exposure to persistent organochlorine compounds through the consumption of fatty fish from the Baltic Sea on human fertility.

Methods Information on time to pregnancy, miscarriages, and subfertility was collected retrospectively by selfadministered questionnaires in two cohorts of fishermen's sisters from the Swedish east coast, by the Baltic Sea, and the west coast, where fish are less contaminated. Along with cohort affiliation, fish consumption and growing up in a fishing village or fisherman's family were used as measures of exposure within the eastcoast cohort (ie, the exposed cohort).

Results There was no support for a negative effect of the consumption of fatty Baltic Sea fish on time to pregnancy, miscarriages, or subfertility. On the contrary, some evidence pointed towards a protective effect of fatty fish consumption within both cohorts.

Conclusions No evidence of reduced fertility was found for women who could be assumed to have a high lifetime consumption of fatty fish contaminated by persistent organochlorine compounds. A possible explanation for this finding is that a positive effect of some of the constituents in fatty fish could be strong enough to disguise the hazardous effects of exposure to persistent organochlorine compounds.
\end{abstract}

Key terms food contamination, miscarriage, polychlorinated biphenyls, stillbirth, time to pregnancy.

Exposure to persistent organochlorine compounds (eg, polychlorinated biphenyls) and dioxins, has been found to affect reproductive outcomes in humans, for example, menstrual cycle length (1), occurrence of spontaneous abortions (2, 3), missed abortions (4), and time to pregnancy (5). In animal studies, the primary effects of 2,3,7,8-tetrachlorodibenzo-p-dioxin (TCDD) on female reproduction appear to be decreased fertility and the inability to maintain a pregnancy for the full gestational period (6). Decreased conception rates have also been observed after exposure to polychlorinated biphenyls (PCB) $(7,8)$. However, since fatty fish is rich in long-chain n-3 fatty acids, as well as in minerals, vitamins and high-quality protein, it is fair to assume that such exposure also has positive effects on reproductive outcomes (9-11).

In Sweden, one of the main exposure routes of persistent organochlorine compounds is the consumption of fatty fish from the Baltic Sea, the water on the east coast of Sweden (12,13). Since Swedish fishermen and their families have been found to consume more locally caught fish than referents from the same place of residence (13-16), fishermen's families on the Swedish east coast were considered to form an appropriate population for studying the effects of dietary exposure to persistent organochlorine compounds. The waters on the west coast of Sweden, Kattegatt and Skagerrak, are considerably less contaminated than the Baltic Sea (17). However, the fish consumption among fishermen and their families is similar to that of eastcoast fishermen's families $(13,15)$. Thus fishermen's families on the west coast of Sweden could be used as a reference group for the exposed group on the east coast.

In a previous study among fishermen's wives (5), we found a decrease in fertility, measured as time to pregnancy, for heavy smokers ( $\geq 10$ cigarettes/day) on the

Reprint requests to: Anna Axmon, Department of Occupational and Environmental Medicine, Institute of Laboratory Medicine, University Hospital, SE-221 85 Lund, Sweden. [E-mail: anna.axmon@ymed.lu.se] 
Swedish east coast when these persons were compared with heavy smokers on the west coast. However, within the cohort of eastcoast fishermen's wives, there was no clear-cut association between 2,2',4,4',5,5'-hexachlorobiphenyl (CB-153, a proxy marker of exposure to persistent organochlorine compounds) in plasma and time to pregnancy (18).

Considering the long biological half-times [probably between 1 and 10 years (19)] for many PCB congeners, it is reasonable to assume that, in a population of fish consumers, the body burden of these compounds during the fertile period of life is largely determined by dietary intake during childhood and adolescence. In support of this assumption, growing up in an eastcoast fishing village or in a fisherman's family results in a higher body burden of persistent organochlorine compounds during adult life (20). The percentage of women with this background is higher among fishermen's sisters than among fishermen's wives (16). Thus fishermen's sisters can be considered an even more adequate study group than fishermen's wives.

The purpose of this study was to assess the effect of the dietary intake of persistent organochlorine compounds on time to pregnancy and the occurrence of miscarriages by comparing a cohort of fishermen's sisters from the east coast of Sweden (exposed group) to a cohort of fishermen's sisters from the Swedish west coast (reference group).

\section{Subjects and methods}

\section{Study cohorts and questionnaire}

Cohorts of fishermen from the east and west coasts of Sweden have been established previously $(14,21)$. In order to identify all sisters (at least one parent in common) to these men, the national Swedish population registry for the period 1945 through 1979 was linked by the national bureau of statistics (Statistics Sweden). Women who were also wives or ex-wives of fishermen were excluded ( $\mathrm{N}=46$ for the east coast, $\mathrm{N}=302$ for the west coast) since they have been previously investigated $(5,18,22)$. Also excluded were two women from each cohort who were unlisted in the population register and women who had emigrated $(\mathrm{N}=32$ for the east coast and $\mathrm{N}=43$ for the west coast) or were deceased ( $\mathrm{N}=8$ for the east coast and $\mathrm{N}=47$ for the west coast).

Postal questionnaires were sent to the remaining sisters $(\mathrm{N}=1241$ for the east coast and $\mathrm{N}=2023$ for the west coast) to collect information on fish consumption and reproductive outcomes. After two reminders the respective response rates were $57 \%(\mathrm{~N}=709)$ and $55 \%$ $(\mathrm{N}=1103)$. However, some of the women did not sup- ply information on all outcome variables, and hence the analyses were based on a somewhat lower number of women (see the section on nonrespondents and missing information).

\section{Outcome variables}

Three different outcomes were used. Time to pregnancy was assessed for each woman's first planned pregnancy. A sequence of questions was used to assess the time to pregnancy: Did you get pregnant the first month of trying?; If not, did you get pregnant the second month?; If not, how many months did it take you to get pregnant? However, before answering these questions the women were asked about the date they stopped using contraceptives, and the date when they got pregnant. This information was never intended to be used in any analysis but was rather an aid to help the women think about their time to pregnancy in terms of months.

The outcome miscarriage or stillbirth was assessed for the first planned pregnancy by asking about the outcome of that pregnancy.

The women who stated that they, at some point in their life, had unsuccessfully tried to get pregnant for a consecutive period of more than 12 months, as well as women who had conceived in their first planned pregnancy as a result of medical treatment, were defined as subfertile.

\section{Exposure variables and potential confounders}

Our primary exposure variable was cohort affiliation. Furthermore, within the eastcoast cohort (ie, the exposed cohort), the following proxy measures of the body burden of persistent organochlorine compounds were used: growing up in a fishing village or fisherman's family and a high current consumption of fatty fish from the Baltic Sea. The latter was assessed by using open-ended questions on the amount of fish consumed. In the original questionnaire we asked about the consumption of fatty and lean Baltic Sea fish and fish caught at "other locations" (however, not specifically on the west coast of Sweden). In order to collect specific information on locally caught fish consumed by the women in the westcoast cohort, we sent a second questionnaire to the women who had agreed to participate in further studies. Out of 364 such women, $262(72 \%)$ answered the second questionnaire. The consumption of locally caught fatty fish within the westcoast cohort was then used to assess the positive effects of seafood consumption (9-11). We aimed at categorizing the consumption of locally caught fatty fish into equally sized groups as low, medium, or high. However, since many women reported identical fish consumption habits, the three groups came to differ somewhat in size (table 1). 
Furthermore, due to the comparatively low number of westcoast women who supplied information on fatty fish consumption, the "low" and "medium" groups were grouped together in the analyses.

Smoking habits during the period prior to conception were assessed by a yes-no question, with a followup question on the number of cigarettes smoked per day for smokers, for both the woman and her partner. Information on alcohol consumption during the same period was also collected for both the woman and her partner, with separate open-ended questions for wine, beer, and strong spirits. A check box was used to indicate that no alcohol had been consumed during the period prior to conception.

Work status was assessed as part-time, full-time, or no time (unemployed, student or housewife). Data on use of oral contraceptives, shift and night work, and heavy lifts were collected using yes-no questions. Year of conception, parity of the first planned pregnancy, age at first menstruation, and length of menstrual cycle were

Table 1. Fish consumption and other background characteristics for the 1812 women (east $\mathrm{N}=709$ west $\mathrm{N}=1103$ ) included in a study of the effect of dietary intake of persistent organochlorine compounds on fertility. ( $95 \% \mathrm{CR}=95 \%$ center range)

\begin{tabular}{|c|c|c|c|c|c|c|c|c|}
\hline & \multicolumn{4}{|c|}{ East coast } & \multicolumn{4}{|c|}{ West coast } \\
\hline & $\mathrm{N}$ & $\%$ & Median & $95 \% \mathrm{CR}$ & $\mathrm{N}$ & $\%$ & Median & $95 \% \mathrm{CR}$ \\
\hline \multicolumn{9}{|l|}{ General background data } \\
\hline Total fish consumption (meals per month) & . & . & 4 & $0-14$ & . & . & 4 & $0-13$ \\
\hline Consumption of locally caught fatty fish a & . & . & 1 & $0-8$ & . & . & 2 & $0-8$ \\
\hline Low ( $\leq 0.5$ meals per month) & 175 & 28 & $\cdot$ & . & 45 & 19 & $\cdot$ & $\cdot$ \\
\hline Medium (1-1.5 meals per month) & 236 & 37 & . & . & 76 & 31 & . & . \\
\hline High ( $\geq 2$ meals per month) & 222 & 35 & . & . & 121 & 50 & . & . \\
\hline Fishing village or fisherman's family & 455 & 65 & . & $\cdot$ & 811 & 74 & $\cdot$ & $\cdot$ \\
\hline Year of birth & $\cdot$ & $\cdot$ & 1957 & $1946-1980$ & $\cdot$ & $\cdot$ & 1958 & $1945-1980$ \\
\hline Ever pregnant or number of pregnancies & 621 & 89 & 2 & $0-10$ & 959 & 88 & 2 & $0-11$ \\
\hline \multicolumn{9}{|l|}{ Education } \\
\hline Elementary school (9 years) & 184 & 26 & . & . & 256 & 24 & . & . \\
\hline High school & 329 & 47 & . & . & 503 & 46 & . & . \\
\hline College or university & 186 & 27 & . & . & 328 & 30 & . & . \\
\hline \multicolumn{9}{|l|}{ Period prior to conception } \\
\hline Year of conception & $\cdot$ & . & 1979 & 1965-1998 & . & . & 1982 & 1965-1998 \\
\hline Age at conception & $\cdot$ & $\cdot$ & 23 & $16-36$ & $\cdot$ & $\cdot$ & 24 & $17-36$ \\
\hline Nulliparous & 431 & 71 & $\cdot$ & $\cdot$ & 737 & 77 & $\cdot$ & $\cdot$ \\
\hline Use of oral contraceptives & 295 & 50 & . & . & 357 & 39 & . & . \\
\hline \multicolumn{9}{|l|}{ Work } \\
\hline Full-time & 427 & 71 & . & . & 674 & 72 & . & . \\
\hline Part-time & 97 & 16 & . & . & 138 & 15 & . & . \\
\hline Unemployed & 14 & 2 & . & . & 21 & 2 & . & . \\
\hline Student & 37 & 6 & . & . & 51 & 5 & . & . \\
\hline Housewife & 26 & 4 & . & . & 48 & 5 & . & . \\
\hline Shift work ${ }^{b}$ & 140 & 27 & . & . & 198 & 25 & . & . \\
\hline Night shift ${ }^{b}$ & 54 & 10 & . & . & 77 & 10 & . & . \\
\hline Heavy lifts & 302 & 52 & . & . & 391 & 44 & . & $\cdot$ \\
\hline Smoker (cigarettes/day) & 294 & 49 & 10 & $4-24^{c}$ & 362 & 39 & 10 & $4-20^{c}$ \\
\hline Partner smoker (cigarettes/day) & 300 & 50 & 15 & $4-30^{c}$ & 327 & 35 & 15 & $4-30^{c}$ \\
\hline \multicolumn{9}{|l|}{ Alcohol consumption } \\
\hline Wine (glasses/week) & . & . & 2 & $0-5^{d}$ & . & . & 2 & $0-5^{d}$ \\
\hline Beer (bottles/week) & . & . & 0 & $0-4^{d}$ & . & . & 0 & $0-5^{d}$ \\
\hline Spirits (cl/week) & . & $\cdot$ & 0 & $0-15^{d}$ & . & . & 0 & $0-10^{d}$ \\
\hline Did not drink & 318 & 55 & . & $\cdot$ & 505 & 56 & . & . \\
\hline \multicolumn{9}{|l|}{ Partner's alcohol consumption } \\
\hline Wine (glasses/week) & . & . & 1 & $0-8^{d}$ & . & . & 1 & $0-5^{d}$ \\
\hline Beer (bottles/week) & . & . & 2 & $0-10^{d}$ & . & . & 2 & $0-10^{d}$ \\
\hline Spirits (cl/week) & . & . & 4 & $0-75^{d}$ & . & . & 0 & $0-40^{d}$ \\
\hline Did not drink & 172 & 30 & . & . & 331 & 37 & . & . \\
\hline
\end{tabular}


assessed using open-ended questions, and education was determined using check boxes for three different levels of education.

Age at conception was calculated using year of birth and year of conception.

The preceding variables were all considered potential confounders, and the distribution in the two cohorts is described in table 1. Since the contamination of Baltic Sea fatty fish has been decreasing over time (15), the year of birth of the woman was evaluated as an effect modifier rather than as a confounder.

The eastcoast women were more likely to have used oral contraceptives and to have performed heavy lifts prior to their first planned pregnancy. Furthermore, there was a higher percentage of smokers among the eastcoast women and their partners, and there were fewer nondrinkers among the partners of the eastcoast women than among the westcoast women. The other potential confounders differed only marginally between the cohorts.

Within the eastcoast cohort, women with a high consumption of fatty fish were older than those with low consumption (data now shown). As a consequence, the pregnancies in this group tended to occur earlier. Furthermore, as a group, these women were less educated and tended to use oral contraceptives to a less extent than the women with a low consumption of fatty fish. The women who had grown up in a fishing village or a fisherman's family had a lower parity for the first planned pregnancy, were more likely to perform heavy lifts, and were more likely to have a job that required shift work than the women who had not grown up in this setting.

\section{Nonrespondents and missing information}

Information about the nonrespondents was available on a group basis from different registers of Statistics Sweden. It was found that the nonrespondents from both coastlines tended to be older than the respondents (Pearson's chi-square $\mathrm{P}<0.001)$. Among the respondents $56 \%$ (east $58 \%$ and west $55 \%$ ) were older than 40 years of age, whereas the corresponding number among the nonrespondents was $63 \%$ (east $64 \%$ and west $63 \%$ ). The nonrespondents were also less educated $(\mathrm{P}<0.001)$ than the respondents, with only $12 \%$ (east $11 \%$ and west $13 \%$ ) having a college or university education compared with 25\% (east 23\% and west 27\%) among the respondents. [These figures from Statistics Sweden differ slightly from the information collected from the respondents by our questionnaire (table 1)]. Furthermore, there was a higher percentage of women who had never given birth among the nonrespondents as compared with the respondents $(\mathrm{P}<0.001$, east $18 \%$ versus $13 \%$ and west $22 \%$ versus $14 \%$ ).
Among the respondents who had ever been pregnant, time to pregnancy was missing for $67(11 \%)$ east- and $109(11 \%)$ westcoast women, and information on pregnancy outcome was missing for $63(10 \%)$ and $75(8 \%)$ of the east- and westcoast women, respectively. Among these women, 39 east- and 56 westcoast women had missing information for both outcome variables. Data on subfertility was missing for $6(1 \%)$ and $9(1 \%)$ eastand westcoast women, respectively.

There was a higher $(\mathrm{P}=0.02)$ percentage of westcoast women who had ever experienced a miscarriage among those who agreed to participate in further studies (30\%) as compared with those who did not (24\%). Otherwise there were no differences in reproductive outcomes between those in the westcoast cohort who did and did not agree to participate or between those who did and did not answer the second questionnaire.

\section{Statistics}

Logistic regression of survival data was employed to estimate the effects of cohort affiliation, growing up in a fishing village or fisherman's family, and fish consumption on time to pregnancy. The rationale for using the logistic regression model comes from the discrete linear logistic model (23), which is applicable when survival time is discrete (24). For each comparison, a success odds ratio (SOR) was calculated from the odds ratio (OR) of each time interval (1-1.9, 2-2.9, etc). The model assumption that odds ratios are similar for each time interval was checked using an interaction term between time and interval. Success odds ratios are similar to effect estimates obtained from an analysis based on the proportional hazards model when the event rates are small in each interval and the follow-up period is relatively short (24). Note that since the success odds ratios measure positive events (wanted pregnancies), a value of $<1$ indicates a prolonged time to pregnancy as compared with that of the reference group.

According to recommendations by Baird et al (25), time to pregnancy was censored at 12 months with a result of 43 east- and 57 westcoast censored observations. Furthermore 59 (east $\mathrm{N}=21$, west $\mathrm{N}=38$ ) women had checked the "no" boxes for achieving pregnancy in the first or second month but had not given a time to pregnancy. These women were included in the time-to-pregnancy analysis but censored at two months. All women who stated that their pregnancy was a result of medical treatment (east $\mathrm{N}=16$, west $\mathrm{N}=37$ ) were included in the analysis. For these women it was assumed that time to pregnancy was longer than 12 months even if time to pregnancy was missing, since this is normally the earliest time point when medical treatment is introduced.

In order to control bias due to birth control failure [ie, if some couples reported that the pregnancy was 
planned even though it occurred as a result of birth control failure (26)], we repeated the analysis of cohort affiliation after excluding data on first-month pregnancies.

The frequency of miscarriages in the first planned pregnancy was calculated but induced abortions, extrauterine pregnancies, and still ongoing pregnancies were excluded. For comparisons of miscarriage rates and subfertility, odds ratios and 95\% confidence intervals (95\% CI) were calculated with the use of a logistic regression.

Multivariate logistic regression analyses were performed with the confounders presented earlier included. When selecting confounders for the multivariate analyses, we used the method suggested by Greenland (27). Starting with the univariate model, we entered variables into bivariate and multivariate models if they changed the effect estimate by $10 \%$ or more, and we excluded them if exclusion changed the effect estimate by less than $5 \%$.

Since the data were consistent with using equidistant intervals between fish consumption categories, such a model was used to test for trend effects between groups for the fish consumption variables. The term significant has been used to represent a P-value of $<0.05$.

\section{Results}

\section{Time to pregnancy}

There was no effect of cohort affiliation on time to pregnancy (SOR 0.99, 95\% CI 0.87-1.14). Excluding women who got pregnant the first month of trying did not change the effect estimate (SOR 0.98, 0.82-1.17). None of the potential confounders changed either effect estimate more than marginally, nor did stratifying according to median year of birth (born in or before 1957 and born in or later than 1958).
In the internal analyses, the consumption of locally caught fatty fish seemed to have a protective, rather than hazardous, effect within both cohorts (table 2). However, no significant dose-response trends were found.

\section{Miscarriages and stillbirths}

The frequencies of miscarriages or stillbirths were similar in the east- (7\%) and westcoast cohorts $(8 \%$, OR $0.86,95 \%$ CI $0.57-1.31)$. The within-cohort analyses showed no consistent effect of either exposure variable on miscarriage risk for the eastcoast women, but a decreased risk was found for the westcoast women with a high current consumption of fatty fish (table 3 ). When age at conception, year of conception, education, parity, alcohol consumption for both the woman and her partner, and the partner's smoking habits were adjusted for, the results were similar to the results obtained without adjustment (data not shown).

\section{Subfertility}

There was no difference in subfertility in the east- $(20 \%)$ and westcoast cohorts (19\%, OR 1.08 , 95\% CI $0.85-$ 1.37). However, when stratification was done by year of birth, there seemed to be a tendency for the older eastcoast women to have a slightly increased risk (OR 1.18, 95\% CI 0.85-1.65). This was not seen for the younger women (OR 0.98, 95\% CI 0.69-1.39). Since some of the subfertile women $(\mathrm{N}=49)$ never conceived, we had no information on background characteristics for the time before pregnancy. Thus only education was possible to test as a confounder. It did not change the effect estimates for cohort comparison more than marginally $(<2 \%)$.

In the internal analyses within the eastcoast cohort, a slight decrease in risk was seen for high exposure for both exposure variables (table 4). With stratification, the positive effect of exposure was found mainly for the

Table 2. Effects of fish consumption and growing up in a fishing village or fisherman's family on time to first planned pregnancy within the cohorts of fishermen's sisters from the east $(\mathrm{N}=709)$ and west $(\mathrm{N}=262)$ coasts of Sweden. Note that, since the outcome is a positive event (pregnancy), an SOR of $<1$ indicates a prolonged time to pregnancy as compared with that of the reference group. (SOR $=$ success odds ratios, $95 \% \mathrm{Cl}=95 \%$ confidence interval)

\begin{tabular}{|c|c|c|c|c|c|c|}
\hline & \multicolumn{3}{|l|}{ East coast } & \multicolumn{3}{|l|}{ West coast } \\
\hline & Median (months) & SOR & $95 \% \mathrm{Cl}$ & Median (months) & SOR & $95 \% \mathrm{Cl}$ \\
\hline \multicolumn{7}{|c|}{ Consumption of locally caught fatty fish a } \\
\hline Low & 2 & 1.00 & . & 2 & $1.00^{b}$ & . \\
\hline Medium & 2 & 1.16 & $0.88-1.53$ & . & . & . \\
\hline High & 1 & 1.27 & $0.96-1.69$ & 2 & 1.36 & $0.96-1.94$ \\
\hline \multicolumn{7}{|c|}{ Fishing village or fisherman's family } \\
\hline No & 2 & 1.00 & $\cdot$ & 2 & 1.00 & $\cdot$ \\
\hline Yes & 2 & 1.12 & $0.89-1.40$ & 2 & 0.98 & $0.80-1.20$ \\
\hline
\end{tabular}

a The fish consumption groups have been defined in table 1.

${ }^{b}$ Low and medium have been grouped to low. 
Table 3. Effects of growing up in a fishing village or fisherman's family and the consumption of locally caught fatty fish on miscarriages within the cohorts of fishermen's sisters from the east $(\mathrm{N}=709)$ and west $(\mathrm{N}=1103)$ coasts of Sweden. $(0 \mathrm{R}=0 \mathrm{dds}$ ratios, $95 \% \mathrm{Cl}=95 \%$ confidence interval)

\begin{tabular}{|c|c|c|c|c|c|c|c|c|}
\hline \multirow[b]{2}{*}{ Exposure } & \multicolumn{4}{|c|}{ East coast } & \multicolumn{4}{|c|}{ West coast } \\
\hline & $\mathrm{N}$ & $\%$ & $\mathrm{OR}$ & $95 \% \mathrm{Cl}$ & $\mathrm{N}$ & $\%$ & $\mathrm{OR}$ & $95 \% \mathrm{Cl}$ \\
\hline \multicolumn{9}{|c|}{ Fishing village or fisherman's family } \\
\hline No & 13 & 7 & 1.00 & $\cdot$ & 16 & 7 & 1.00 & $\cdot$ \\
\hline Yes & 22 & 6 & 0.89 & $0.44-1.81$ & 48 & 8 & 1.08 & $0.60-1.94$ \\
\hline \multicolumn{9}{|c|}{ Current fatty fish consumption $\mathrm{a}, \mathrm{b}$} \\
\hline Low & 10 & 7 & 1.00 & $\cdot$ & 13 & 14 & $1.00^{c}$ & . \\
\hline Medium & 12 & 7 & 0.88 & $0.37-2.09$ & . & . & . & . \\
\hline High & 10 & 6 & 0.73 & $0.29-1.80$ & 3 & 3 & 0.19 & $0.05-0.67$ \\
\hline
\end{tabular}

a The fish consumption groups have been defined in table 1 .

${ }^{\mathrm{b}}$ The west coast data were obtained from a second questionnaire sent only to a subgroup ( $\left.\mathrm{N}=364\right)$ of the women in the cohort. (See the text.)

c Low and medium have been grouped to low.

Table 4. Effects of growing up in a fishing village or fisherman's family and the consumption of locally caught fatty fish on subfertility in the cohorts of fishermen's sisters from the east $(\mathrm{N}=709)$ and west $(\mathrm{N}=1103)$ coasts of Sweden. $(\mathrm{OR}=0 \mathrm{dds}$ ratios, $95 \% \mathrm{Cl}=95 \%$ confidence interval)

\begin{tabular}{|c|c|c|c|c|c|c|c|c|c|c|c|c|}
\hline \multirow[b]{3}{*}{ Exposure } & \multicolumn{8}{|c|}{ East coast } & \multicolumn{4}{|c|}{ West coast } \\
\hline & \multirow[b]{2}{*}{ N } & \multirow[b]{2}{*}{$\%$} & \multicolumn{2}{|l|}{ Total } & \multicolumn{2}{|c|}{ Born before 1957} & \multicolumn{2}{|c|}{ Born after 1958} & \multirow[b]{2}{*}{$\mathrm{N}$} & \multirow[b]{2}{*}{$\%$} & \multicolumn{2}{|l|}{ Total } \\
\hline & & & $\mathrm{OR}$ & $95 \% \mathrm{Cl}$ & $\mathrm{OR}$ & $95 \% \mathrm{Cl}$ & $\mathrm{OR}$ & $95 \% \mathrm{Cl}$ & & & $\mathrm{OR}$ & $95 \% \mathrm{Cl}$ \\
\hline \multicolumn{13}{|c|}{ Fishing village or fisherman's family } \\
\hline No & 59 & 24 & 1.00 & & 1.00 & & 1.00 & & 49 & 17 & 1.00 & \\
\hline Yes & 80 & 18 & 0.67 & $0.46-0.97$ & 0.89 & $0.53-1.52$ & 0.41 & $0.27-0.85$ & 156 & 19 & 1.14 & $0.80-1.62$ \\
\hline \multicolumn{13}{|c|}{ Current fatty fish consumption $\mathrm{a}, \mathrm{b}$} \\
\hline Low & 42 & 24 & 1.00 & & 1.00 & & 1.00 & & 28 & 23 & $1.00^{c}$ & \\
\hline Medium & 49 & 21 & 0.83 & $0.52-1.33$ & 1.04 & $0.53-2.05$ & 0.59 & $0.30-1.16$ & & & & \\
\hline High & 37 & 17 & 0.64 & $0.39-1.06$ & 0.54 & $0.27-1.11$ & 0.63 & $0.30-1.36$ & 25 & 21 & 0.86 & $0.47-1.58$ \\
\hline
\end{tabular}

a The fish consumption groups have been defined in table 1 .

${ }^{\mathrm{b}}$ The west coast data have been taken from a second questionnaire sent only to a subgroup ( $\left.\mathrm{N}=364\right)$ of the women in the cohort. (See the text.)

${ }^{c}$ Low and medium have been grouped to low.

younger women. No significant trend was found for fish consumption. The effects within the westcoast cohort were similar to those in the eastcoast cohort.

\section{Discussion}

No support was obtained for reduced fertility or an increased risk of miscarriage among women with a high intake of fatty fish contaminated with persistent organochlorine compounds in our study; instead indications of a positive effect were found for fatty fish consumption.

As our main outcome, we used the time needed for a couple to achieve a wanted pregnancy. This variable has proved to be a useful tool when reproductive effects of exposures in general (29) and environmental exposure in particular (25) have been assessed retrospectively (28).
The retrospective study design excluded infertile women from the time-to-pregnancy analysis. However, the subfertile women were included in separate analyses and hence were not disregarded.

Women whose pregnancies are all unplanned can never be included in time-to-pregnancy studies. In our cohorts, the percentage of women who were nulliparous at their first planned pregnancy was similar (71\% and $77 \%$ for the east- and westcoast cohorts, respectively). This finding suggests that pregnancy planning bias [ie, that the two cohorts have different rates of unplanned pregnancies (30)] should be of minor concern. When excluding first month pregnancies, the success odds ratio remained the same. Hence bias from birth control failure (26) was not an issue of concern in this study. Moreover, it was unlikely that east- and westcoast women would have differed in their response to fertility problems, and therefore behavior modification bias (26) should not be an issue of concern either. 
For women who recognize their pregnancies late, early miscarriages may be disguised as long time to pregnancy. The number of early miscarriages (before the eighth gestational week) was similarly low in both cohorts [east $\mathrm{N}=3(1 \%)$ and west $\mathrm{N}=8(1 \%)$ ]. Hence pregnancy recognition bias (26) should not have been of major concern. Time trend bias (26) may be of concern since both the consumption of fish and the content of persistent organochlorine compounds in fish had decreased over time. We, however, tried to deal with this problem by stratifying according to the woman's year of birth.

We have previously found cohorts comprised of fishermen's families to be stable with respect to residence. For births that took place in 1973-1975, 90\% of the eastand $97 \%$ of the westcoast fishermen's sisters resided on the same coast as their brothers and, at a conscript examination 18 years later, $88 \%$ (east) and $95 \%$ (west) of the sons of the fishermen's sisters lived on the same coast as their uncles (unpublished data). In our current study, place of residence was only available for the $34 \%$ who agreed to participate in further studies. However, among these women $85 \%$ (east) and $88 \%$ (west) resided on the same coast as their brothers, and only $5 \%$ of the east- and $10 \%$ of the westcoast women resided on the opposite coast. Thus the fact that the cohort affiliation of the fishermen's sisters in our present study was determined by the current residence of their brothers has not resulted in any major misclassification.

In our questionnaire we assessed the major confounders. The socioeconomic status varied little between the fishermen's sisters on the east and west coasts. Thus the possible confounding effect of socioeconomic status was reduced by the use of the westcoast cohort for comparison.

We failed to ask the women about their age when they first started to conceive. One alternative would be to try to calculate the age when a woman first started to conceive by subtracting the time to pregnancy from the age at conception. (See reference 31.) However, this procedure would only have a minor impact on age, since only a few women had very long time to pregnancies (only $2 \%$ of the women had a time to pregnancy longer than 36 months). We therefore chose to use age at conception as a proxy measure of the age when a woman first started trying to conceive.

The response rate of our study was rather low. Among the women who did not respond to our questionnaire, there was a higher percentage of those who had never given birth. The differences were similar in both cohorts, and selection bias with respect to fertility should therefore not be an issue of concern in the cohort comparisons. However, selection bias could not be ruled out in the internal analyses.

Among the westcoast women who answered our second questionnaire, the frequency of first-planned-preg- nancy miscarriages among these women was higher than in any other investigated group. However, there is no reason to believe that this selection was related to fatty fish consumption.

Only $20 \%$ of the women reported a time to pregnancy that was an even 6 months, whereas the corresponding value was $35 \%$ in our previous study on fishermen's wives (5). Before asking the fishermen's sisters about their time to pregnancy, we asked them about the date (year and month) when they stopped using contraceptives, and when they became pregnant. The fishermen's wives were not asked these questions. Thus the use of these supplementary questions has probably reduced digit preference.

Time to pregnancy was missing for almost $10 \%$ of the women. However, it should be born in mind that this percentage probably reflects the proportion of women whose pregnancies were all unplanned. For comparison, in a random sample of some 1600 Swedish women born in 1960, or later, who had been pregnant, $18 \%$ had never planned any of their pregnancies (own data, not published).

The consumption of locally caught fish has been decreasing since the early 1970s (15), and therefore current fish consumption is not necessarily a good proxy for fish consumption up to early pregnancy, which ranged from 1961 to 1999 . We deliberately abstained from asking about fish consumption at the time of conception, or before, since we have shown a low reliability for the long-term recall of fish intake in these cohorts (32). A direct measure of body burden for persistent organochlorine compounds would be a preferable alternative to any form of recalled information.

We have previously studied time to pregnancy in cohorts of fishermen's wives (5), who, to a less extent than the fishermen's sisters, had been exposed to fishrelated environmental contaminants during childhood and adolescence (16). Within the eastcoast cohort we found results similar to those in our present study, with a slight, but not statistically significant, decrease in time to pregnancy from growing up in a fishing village. Such effects were not found among women who consumed fish from the Great Lakes (33), which gives similar exposure levels (34).

The results on miscarriages are consistent with those found for fishermen's wives, among whom a decrease in risk was found for eastcoast compared with westcoast cohort affiliation, as well as for high fatty-fish consumption within the eastcoast cohort (22). Similar results have also been found for women who consumed fish from Lake Ontario (35). However, in a study on women from the Lake Michigan area, no such protective effect was seen (36).

The analyses of subfertility did not show any effect of eastcoast cohort affiliation. However, within the 
eastcoast cohort, the risk seemed to decrease with increasing exposure. This result agrees with the other findings of our present study but not with results found among women who consumed fish from Lake Michigan (37).

Within both cohorts of fishermen's sisters the results pointed towards a slight protective effect of fatty-fish consumption. Other studies have found a positive correlation between the consumption of fatty fish during pregnancy and reproductive outcomes such as birthweight and duration of pregnancy $(9,11)$. Thus a possible interpretation of our results may be that the negative effects of the contamination of Baltic Sea fish are outweighed by the positive effects of other constituents in fatty fish (eg, polyunsaturated fatty acids). A similar interpretation was also suggested by Mendola et al (35) when they failed to find an association between miscarriages and PCB exposure from the consumption of fatty fish from the Great Lakes.

In conclusion, we found no negative effect of exposure to persistent organochlorine compounds on time to pregnancy and miscarriages. However, the exposure assessments were not fully satisfactory. For a better assessment of the relation between the intake of contaminated fish and time to pregnancy, individual exposure biomarkers for persistent organochlorine compounds should be used.

\section{Acknowledgments}

This work was financed by grants the from Swedish National Environmental Protection Board, the Foundation for Strategic Environmental Research, the Swedish Council for Work Life Research, and the Medical Faculty, Lund University.

\section{References}

1. Mendola P, Buck GM, Sever LE, Zielezny M, Vena JE. Consumption of PCB-contaminated freshwater fish and shortened menstrual cycle length. Am J Epidemiol 1997;146:95560.

2. Leoni V, Fabiani L, Marinelli G, Puccetti G, Tarsitani GF, De Carolis A, et al. PCB and other organochlorine compounds in blood of women with or without miscarriage: a hypothesis of correlation. Ecotoxicol Environ Safety 1989;17:1-11.

3. Gerhard I, Daniel V, Link S, Monga B, Runnebaum B. Chlorinated hydrocarbons in women with repeated miscarriages. Environ Health Perspect 1998;106:675-81.

4. Bercovici B, Wassermann M, Cucos S, Ron M, Wassermann D, Pines A. Serum levels of polychlorinated biphenyls and some organochlorine insecticides in women with recent and former missed abortions. Environ Res 1983;30:169-74.
5. Axmon A, Rylander L, Strömberg U, Hagmar L. Time to pregnancy and infertility among women with a high intake of fish contaminated with persistent organochlorine compounds. Scand J Work Environ Health 2000;26:199-206.

6. Peterson RE, Theobald HM, Kimmel GL. Developmental and reproductive toxicity of dioxins and related compounds: cross-species comparisons. Crit Rev Toxicol 1993;23:283335.

7. Barsotti DA, Marlar RJ, Allen JR. Reproductive dysfunction in rhesus monkeys exposed to low levels of polychlorinated biphenyls (Aroclor 1248). Food Cosmet Toxicol 1976;14:99103.

8. Golub MS, Donald JM, Reyes JA. Reproductive toxicity of commercial PCB mixtures: LOAELs and NOAELs from animal studies. Environ Health Perspect 1991;94:245-53.

9. Olsen SF, Grandjean P, Weihe P, Videro T. Frequency of seafood intake in pregnancy as a determinant of birth weight: evidence for a dose dependent relationship. J Epidemiol Community Health 1993;47:436-40.

10. Olsen SF. Consumption of marine n-3 fatty acids during pregnancy as a possible determinant of birth weight: a review of the current epidemiologic evidence. Epidemiol Rev 1993;15:399-413.

11. Odent MR, McMillan L, Kimmel T. Prenatal care and sea fish. Eur J Obstet Gynecol Reprod Biol 1996;68:49-51.

12. Asplund L, Svensson BG, Nilsson A, Eriksson U, Jansson B, Jensen $\mathrm{S}$, et al. Polychlorinated biphenyls, 1,1,1-trichloro2,2-bis(p-chlorophenyl)ethane (p,p'-DDT) and 1,1-dichloro2,2-bis(p-chlorophenyl)- ethylene (p,p'-DDE) in human plasma related to fish consumption. Arch Environ Health 1994:49:477-86.

13. Svensson BG, Nilsson A, Hansson M, Rappe C, Åkesson B, Skerfving S. Exposure to dioxins and dibenzofurans through the consumption of fish. N Engl J Med 1991;324:8-12.

14. Hagmar L, Lindén K, Nilsson A, Norrving B, Åkesson B, Schütz A, et al. Cancer incidence and mortality among Swedish Baltic Sea fishermen. Scand J Work Environ Health 1992;18:217-24.

15. Rylander L, Strömberg U, Hagmar L. Decreased birthweight among infants born to women with a high dietary intake of fish contaminated with persistent organochlorine compounds. Scand J Work Environ Health 1995;21:368-75.

16. Rylander L, Strömberg U, Hagmar L. Lowered birth weight among infants born to women with a high intake of fish contaminated with persistent organochlorine compounds. Chemosphere 2000;40:1255-62.

17. Bergqvist P, Bergek S, Hallbäck H, Rappe C, Slorach S. Dioxins in cod and herring from the seas around Sweden. Chemosphere 1989;19:513-6.

18. Axmon A, Rylander L, Strömberg U, Dyremark E, Hagmar L. Polychlorinated biphenyls in blood plasma among Swedish female fish consumers in relation to time to pregnancy. J Toxicol Environ Health. In press.

19. Shirai JH, Kissel JC. Uncertainty in estimated half-lives of PCBs in humans: impact on exposure assessment. Sci Total Environ 1996;187:199-210.

20. Rylander L, Dyremark E, Strömberg U, Östman C, Hagmar L. The impact of age, lactation and dietary habits on PCB in plasma in Swedish women. Sci Total Environ 1997;207:5561.

21. Svensson BG, Mikoczy Z, Strömberg U, Hagmar L. Mortality and cancer incidence among Swedish fishermen with a high dietary intake of persistent organochlorine compounds. Scand J Work Environ Health 1995;21:106-15. 
22. Axmon A, Rylander L, Strömberg U, Hagmar L. Miscarriages and stillbirths in women with a high intake of fish contaminated with persistent organochlorine compounds. Int Arch Occup Environ Med 2000;73:204-8.

23. Cox D. Regression models and life tables. JR Stat Soc 1972;34:187-220.

24. Hosmer D, Lemeshow S. Applied logistic regression. New York (NY): John Wiley \& Sons, 1989.

25. Baird DD, Wilcox AJ, Weinberg CR. Use of time to pregnancy to study environmental exposures. Am J Epidemiol 1986;124:470-80.

26. Weinberg CR, Baird DD, Wilcox AJ. Sources of bias in studies of time to pregnancy. Stat Med 1994;13:671-81.

27. Greenland S. Modeling and variable selection in epidemiologic analysis. Am J Public Health 1989;79:340-9.

28. Joffe M. Feasibility of studying subfertility using retrospective self reports. J Epidemiol Community Health 1989; 43:268-74.

29. Joffe M. Time to pregnancy: a measure of reproductive function in either sex: Asclepios project. Occup Environ Med 1997;54:289-95.

30. Baird DD, Weinberg CR, Wilcox AJ. Planning bias in timeto-pregnancy studies. In: Campbell K, Woods J, editors. Human reproductive ecology: interactions of environment, fertility and behavior. New York: New York Academy of Sciences, Research Triangle Park, NC, 1993.

31. Sallmen M, Luukkonen R. Is the observed association be- tween increasing paternal age and delayed conception an artefact? Hum Reprod 2001;16:2027-8.

32. Rylander L, Strömberg U, Hagmar L. Agreement between reported fish consumption obtained by two interviews and its impact on the results in a reproduction study. Eur J Epidemiol 1998;14:93-7.

33. Buck GM, Sever LE, Mendola P, Zielezny M, Vena JE. Consumption of contaminated sport fish from Lake Ontario and time-to-pregnancy: New York State angler cohort. Am J Epidemiol 1997;146:949-54.

34. Ahlborg U, Hanberg A, Kenne K. Risk assessment of polychlorinated biphenyls (PCBs). In: Proceedings from the Nordic Council of Ministers. Copenhagen: Nordic Council of Ministers, 1992:26.

35. Mendola P, Buck GM, Vena JE, Zielezny M, Sever LE. Consumption of PCB-contaminated sport fish and risk of spontaneous fetal death. Environ Health Perspect 1995; 103:498-502.

36. Dar E, Kanarek MS, Anderson HA, Sonzogni WC. Fish consumption and reproductive outcomes in Green Bay, Wisconsin. Environ Res 1992;59:189-201.

37. Courval JM, DeHoog JV, Stein AD, Tay EM, He J, Humphrey HE, et al. Sport-caught fish consumption and conception delay in licensed Michigan anglers. Environ Res 1999;80:S183-8.

Reveived for publication: 5 October 2001 